\title{
Phenolic and flavonoid contents and antioxidant activity of an endophytic fungus Nigrospora sphaerica (EHL2), inhabiting the medicinal plant Euphorbia hirta (dudhi) L.
}

\author{
Veer Singh Gautam ${ }^{1,2}$ - Arti Singh ${ }^{1}$ - Puja Kumari ${ }^{1}$ - Jay Hind Nishad ${ }^{1}$ - Jitendra Kumar ${ }^{1}$ - Monika Yadav ${ }^{1}$. \\ Rajnish Bharti ${ }^{1}$ - Priyanka Prajapati ${ }^{1}$ - Ravindra Nath Kharwar ${ }^{1}$ (D)
}

Received: 11 August 2021 / Revised: 5 October 2021 / Accepted: 7 October 2021 / Published online: 17 January 2022

(c) The Author(s), under exclusive licence to Springer-Verlag GmbH Germany, part of Springer Nature 2022

\begin{abstract}
Since endophytic fungi are pivotal sources of various bioactive natural compounds, the present study is aimed to investigate the antioxidant compounds of the endophytic fungus Nigrospora sphaerica isolated from a pantropical weed, Euphorbia hirta $\mathrm{L}$. The fungus was fermented in four different media and each filtered broth was sequentially extracted in various solvents. Crude extracts collected from different solvents were subjected to phytochemical analysis and antioxidant activity. The total phenolic content (TPC) and total flavonoid content (TFC) were maximal in ethyl acetate crude extract (EtOAcE) of endophyte fermented in potato dextrose broth (PDB) medium $(77.74 \pm 0.046 \mathrm{mgGAE} / \mathrm{g}$ and $230.59 \pm 2.0 \mathrm{mgRE} / \mathrm{g}$ ) with the highest $96.80 \%$ antioxidant activity. However, TPC and TFC were absent in hexane extract of Czapek Dox broth (CDB) medium exhibiting the lowest $4.63 \pm 2.75 \%$ activity. The EtOAcE (PDB) showed a positive correlation between TFC and antiradical activity $\left(R^{2}=0.762 ; P<0.05\right)$, whereas a high positive correlation was noticed between TPC and antioxidant activity $\left(R^{2}=0.989 ; P<0.05\right)$. Furthermore, to determine the antioxidant activity, EtOAcE (PDB) was subjected to TLC bioautography-based partial purification, while GC/MS analysis of the partial purified extract was done to confirm the presence of phenolics along with antioxidant compounds that resulted in the detection of 2,4-Di-tert-butylphenol (13.83\%), a phenolic compound accountable for the antioxidant potential. Conclusively, N. sphaerica is a potential candidate for natural antioxidant.
\end{abstract}

Communicated by Erko Stackebrandt.

Ravindra Nath Kharwar

rnkharwar@gmail.com; rnkharwarbot@bhu.ac.in

1 Mycopathology and Microbial Technology Laboratory, Centre of Advanced Study (CAS) in Botany, Institute of Science, Banaras Hindu University, Varanasi 221005, India

2 Wood Properties and Uses Division, Institute of Wood Science and Technology, Bengaluru 560003, India 


\section{Graphical abstract}

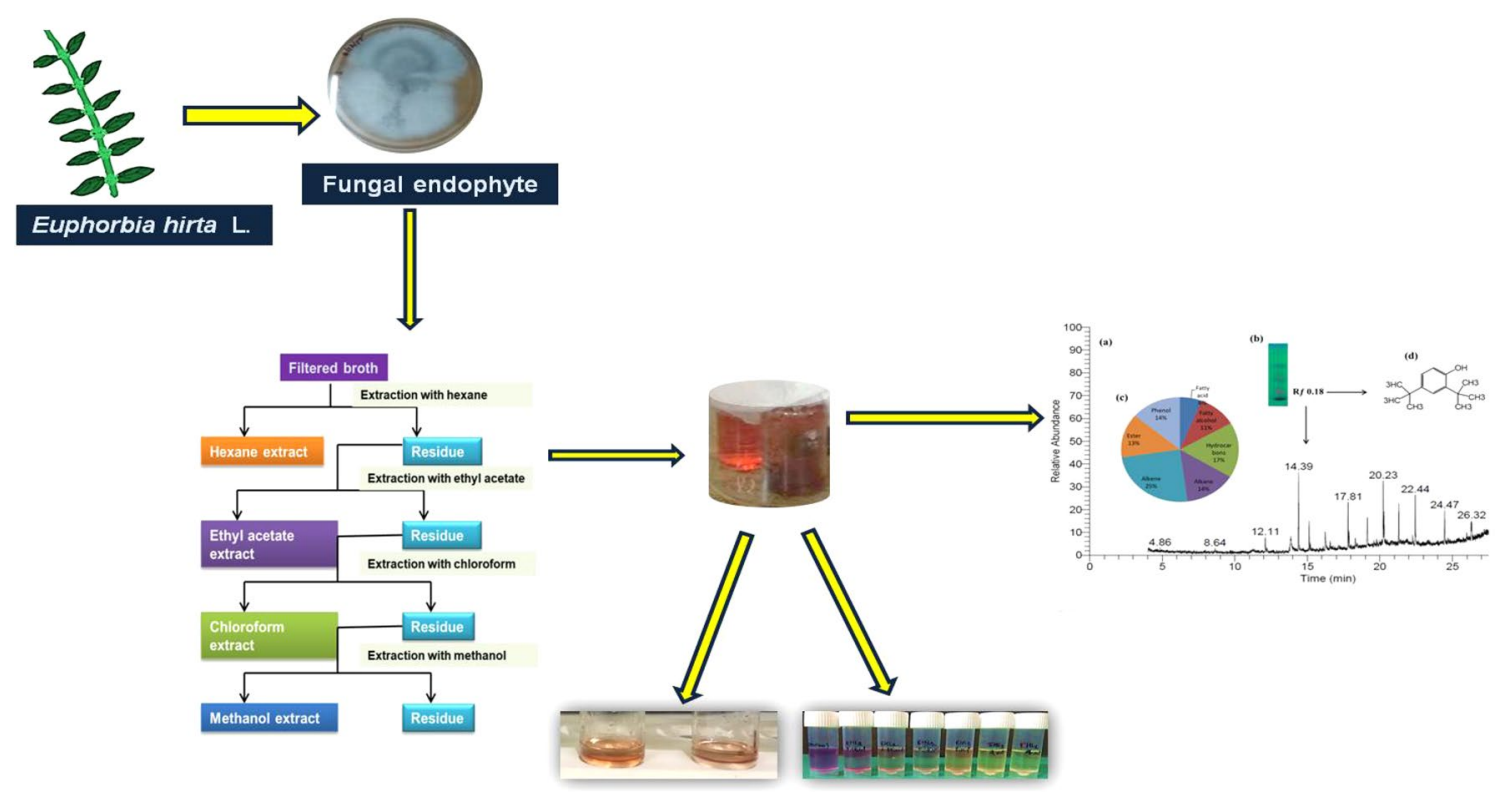

Keywords N. sphaerica Phytochemical analysis - TLC bioautography $\cdot$ Compounds purification - Antioxidant activity . GC-MS analysis

\section{Introduction}

Oxidative stress/damage, caused by endogenous factors, such as reactive oxygen species (ROS) including the hydroxyl radical, superoxide anion, hydrogen peroxide, nitric oxide radical, singlet oxygen and hypochlorite radical, and exogenous factors, such as ionizing radiation, smoking, pollution, pesticides and organic solvents, can cause damage to biomolecules, like nucleic acids, lipids, proteins and enzymes, which may be the reasons for loss of structure and function, and eventually leading to several chronic diseases, such as cancer, diabetes, atherosclerosis, rheumatoid arthritis, cardiovascular disease, chronic inflammation, stroke, aging, septic shock and other degenerative disease in human (Fang et al. 2002). Natural antioxidant compounds play a significant role in reducing oxidative stress/damage and to improve the immune function via inhibiting diseases by scavenging radicals (Tan et al. 2018).

In the human body, there is a sort of balance between the number of free radicals generated and antioxidants (Mau et al. 2002). Excessive generation of ROS may result in oxidative damage, mutation, cytotoxicity and cell death due to the structural change of cellular molecules (Kohen and Nyska 2002). Various types of synthetic antioxidant compounds, like butylated hydroxytoluene (BHT), butylated hydroxyanisole (BHA) and tertiary butyl hydroquinone (TBHQ), have already been used as food preservatives or in food to prevent oxidation. However, the use of synthetic antioxidants in food is discouraged because of their carcinogenicity and toxicity (Sun and Fukuhara 1997). Hence, antiradical compounds isolated, especially from natural sources, may have potential application in preventing/curing diseases and making them capable of protecting ROS-mediated oxidative damage.

The literature survey reveals that the plant Euphorbia hirta contains several antioxidant compounds, such as gallic acid, quercetin, rutin and euphorbin-A,B,C,D (Muhammad et al. 2012). Endophytic fungi reside in a symbiotic manner inside its host plant, and can produce the same bioactive natural compounds for which the plant is known (Kumari et al. 2021). Several host origin compounds, such as azadirachtin, berberine, camptothecin, piperine, podophyllotoxin, rohitukine, vinblastine, vincristine and taxol, have been reported from fungal endophytes (Singh et al. 2021). The possibility of intergenic genetic exchange between a fungus and the host plant has been suggested. Such substitute sources of endophytic fungi may reduce the overexploitation of host medicinal plants and the cost of host mimetic natural compounds (Verma et al. 2009; Su et al. 2012). Recently, an antimicrobial compound "phomalactone" has been reported from a fungal endophyte, Nigrospora sphaerica isolated from Adiantum philippense (Ramesha et al. 2020). There are several reports that Nigrospora sp produces antimicrobial compounds, such as nigrosporins, nigrosporolides and 
lactones. However, until date, little study has been done on the antioxidant natural compounds produced by Nigrospora sphaerica.

The present report narrates the isolation of a fungal endophyte, Nigrospora sphaerica, from healthy leaf tissues of the medicinal plant, Euphorbia hirta, with the aim of investigating the antioxidant compounds through TLC bioautography-based detection, and purification of antioxidant compounds, followed by identification of compounds using GCMS technique. Besides, phytochemical analysis of sequentially extracted crude metabolites and their correlation with antioxidant activity was also established. To the best of our knowledge, this is the first elaborative and exclusive report on antioxidant compounds produced by $N$. Sphaerica of E. hirta L.

TPC, total phenolic content: TFC, total flavonoid content: EtOAcE, ethyl acetate extract: $\mathrm{PDB}$, potato dextrose broth: CDB, Czapek Dox broth: SDB, Sabouraud dextrose broth: CDYEB, Czapek Dox yeast extract broth: MEB, malt extract broth: ABTS, 2,2'-azino-bis(3-ethylbenzothiazoline6-sulfonicacid): DPPH, 2,2-diphenyl-1-picrylhydrazyl:TLC, thin layer chromatography: GAE, gallic acid equivalent: RE, rutin equivalent: ITS, internal transcribed spacer: AA, ascorbic acid: QR, quercetin: GCMS, gas column mass spectroscopy.

\section{Materials and methods}

\section{Isolation of fungal isolate}

Mature, healthy and disease-free leaf samples of the medicinally important plant Euphorbia hirta were collected randomly from the Botanical Garden, Banaras Hindu University (BHU) Varanasi, India. To remove epiphytes, the samples were initially surface sterilized using standard protocol (Sharma et al. 2017) with certain modifications. The endophytic fungus was isolated from the leaves of E. hirta, a plant belonging to the family Euphorbiaceae. For surface sterilization, leaves were treated with $70 \%$ ethyl alcohol for $1 \mathrm{~min}$, followed by immerging in 4\% sodium hypochlorite solution for $1 \mathrm{~min}$ before ringing in $70 \%$ ethyl alcohol for $30 \mathrm{~s}$. The sterilized samples were ringed in distilled water and allowed to dry between autoclaved blotting paper. The samples were cut into small pieces $(0.5 \times 0.5 \mathrm{~cm}$ squares $)$, and placed onto Petri plates containing potato dextrose agar (PDA) medium supplemented with $100 \mu \mathrm{g} / \mathrm{ml}$ streptomycin. All the Petri dishes were sealed with Parafilm and incubated at $26 \pm 2{ }^{\circ} \mathrm{C}$ in a BOD cum humidity incubator (Caltan, Narang Scientific Works, New Delhi), and monitored every day for fungal emergence for up to 20 days. The sterilized tissue imprinted control blank PDA plate and plates having tissue segments to check the probability of contamination throughout the incubation period were also incubated (Sharma et al. 2017). Endophytes emerging from explants that showed variation in morphology (colour, growth pattern) were transferred and maintained on freshly prepared PDA plates as axenic cultures.

\section{Identification of fungal isolate by morphological and molecular method}

Preliminarily, the fungal isolate was identified based on morphological features. Moreover, fungal identity was confirmed by molecular characterization after sequencing of the ITS-rDNA portion. For that, total genomic DNA was isolated from the freshly grown endophytic fungus, EHL2, using a standard method (Verma et al. 2014) with little modifications. The universal primers ITS1 (5'TCCGTA GGTGAACCTGCGG3') and ITS4 (5'TCCTCCGCTTAT TGATATGC3') were used to amplify the 5.8S rDNA and two ITS regions between the 18S and 28S rDNA in Mycycler unit (BioRad, United States) through polymerase chain reaction (PCR). The sample was amplified in total of 25 $\mu \mathrm{L}$ PCR reaction mixture containing $0.25 \mu \mathrm{L}$ Taq polymerase enzyme, $1 \mu \mathrm{L}$ of primer (ITS1 or ITS 4$), 1 \mu \mathrm{L}$ (120 ng/ $\mu \mathrm{L})$ DNA sample, $0.5 \mu \mathrm{L}$ dNTPs, $2.5 \mu \mathrm{L} 10 \times$ PCR buffer with $25 \mathrm{mM} \mathrm{MgCl} 2$ and $18.75 \mu \mathrm{L}$ milli Q water. Amplification was carried out under the following cycle profile: pre-denaturation at $95{ }^{\circ} \mathrm{C}(5 \mathrm{~min})$, followed by 35 cycles of each denaturation at $94{ }^{\circ} \mathrm{C}(1 \mathrm{~min})$, annealing at $54{ }^{\circ} \mathrm{C}$ (1 min), extension at $72{ }^{\circ} \mathrm{C}$ for $1.30 \mathrm{~min}$ and a final extension at $72{ }^{\circ} \mathrm{C}$ for $5 \mathrm{~min}$. The quality and integrity of the resulting PCR products were tested on $1.5 \%$ agarose gel impregnated with $\operatorname{EtBr}\left(0.5 \mu \mathrm{gmL}^{-1}\right)$ and visualized under an ultraviolet transilluminator. The amplified PCR amplicon was purified by HiYield PCR DNA mini kit (Real Biotech Corporation, India) through gel excision method. Purified ITS fragments were carried out for sequencing by Agri Genome Labs Pvt. Ltd., Kerala, India. Furthermore, the obtained sequence was submitted to the GenBank database of NCBI for accession number and identification.

\section{Fermentation and sequential extraction of crude extract from fungal endophyte}

Mycelial disc (5 mm) of freshly grown endophytic EHL2 was cultured in 500-ml Erlenmeyer flasks, each containing $200 \mathrm{ml}$ of different media. All the five different culture media (Himedia), i.e. potato dextrose broth (PDB), Czapek Dox broth (CDB), Czapek Dox yeast extract broth (CDYEB), malt extract broth (MEB) and Sabouraud dextrose broth (SDB), were adopted for fermentation and incubated at $26 \pm 2{ }^{\circ} \mathrm{C}$. After 21 days of incubation, mycelia of all the cultures were filtered through muslin cloth. Each filtered broth was extracted thrice (1:1 ratio) in each organic solvent 
sequentially using a separating funnel in the increasing order of relative polarity: hexane, ethyl acetate, chloroform and methanol, respectively. Each crude extract was concentrated using the rota evaporator (IKA RV 10, IKA, Staufen, Germany) on $65 \mathrm{rpm}$ at $40{ }^{\circ} \mathrm{C}$, dried slowly under a fume hood and stored at $4{ }^{\circ} \mathrm{C}$ until used for biological activity.

\section{Lyophilization}

The residue obtained after extraction in chloroform was miscible in methanol solvent; the samples were lyophilized. Finally, the freeze-dried samples were dissolved in methanol for testing biological activity.

\section{Qualitative phytochemical analysis of sequentially extracted crude metabolites of the fungal isolate}

Sequentially extracted crude extracts of endophytic $N$. sphaerica were tested for the presence of the following secondary metabolites: phenolics (Devi et al. 2012), flavonoids (Tepal 2016), alkaloids (Mayer's reagent) (Ajuru et al. 2017), terpenoids (Abdel-Rahman et al. 2019) and glycosides (KellerKiliani test for digitoxose) with little modifications.

\section{Determination of total contents of phenolic (TPC) and flavonoid (TFC)}

The total phenolic content (TPC) of each extract was determined using Folin-Ciocalteu reagent (Siddhuraju and Manian 2007) with minor modifications. For this, $10 \mu \mathrm{L}$ containing $1 \mathrm{mg}$ of extract was mixed with $990 \mu \mathrm{L}$ of double distilled water. Then, half a millilitre of $2 \mathrm{~N}$-Folin-Ciocalteau phenol reagent was added to the vial, followed by the mixing of $2.5 \mathrm{~mL}$ of sodium carbonate (20\%), and incubated in a dark room for $40 \mathrm{~min}$. Absorbance of the solution was recorded at $725 \mathrm{~nm}$ using a UV-visible spectrophotometer against a reagent blank. Quantification of TPC was done using gallic acid standard curve. The results are expressed as gallic acid equivalent (mg GAE/g of crude extract). However, total flavonoid content (TFC) was evaluated applying the protocol of Zhishen et al (1999). For that, $0.5 \mathrm{~mL}$, containing a concentration of $2 \mathrm{mg} / \mathrm{mL}$ of each extract, was taken in a separate plastic vial to which was added $2 \mathrm{~mL}$ of double distilled water, followed by subsequent well mixing of $150 \mu \mathrm{L}$ of sodium nitrite (5\%) solution. After $5 \mathrm{~min}, 150$ $\mu \mathrm{L}$ of $\mathrm{AlCl}_{3}(10 \%)$ solution was put in the vial, followed by the addition of $2 \mathrm{~mL}$ of sodium hydroxide (4\%) solution. The final volume of the mixture was maintained to $5 \mathrm{~mL}$ by adding water. The mixtures were shaken well and allowed to stand at room temperature for $15 \mathrm{~min}$. Absorbance was read at $510 \mathrm{~nm}$. Rutin was used as a standard curve to quantify the TFC, and the results are expressed as (mg RE/g crude extract). All the experiments were performed in triplicate.

\section{TLC bioautography-based detection and purification of antioxidant compounds}

A TLC bioautography was performed to screen the antioxidant compounds present in the crude extract (Belaqziz et al. 2017). For this, $200 \mu \mathrm{g}$ of EtOAcE (PDB) was separately applied on a chromatographic silica plate $(5 \mathrm{~cm} \times 10 \mathrm{~cm}$, Merck, TLC grade) as a stationary phase. Ethyl acetate and hexane $(1: 1)$ were used as a mobile phase to perform the chromatography. Silica plate was observed pre and post derivatization (0.2 Mm DPPH solution) under visible, short UV light $(254 \mathrm{~nm})$ and long UV light $(366 \mathrm{~nm})$ in the UV-visible chamber. The mode of each separating spot of extract was expressed as a retention factor ( $\mathrm{R} f$ ) value, and $\mathrm{R} f$ was calculated as follows:

$\mathrm{R} f=$ Distance travel by solute from the centre of spot loading point/Distance travel by solvent front.

After partition on a silica plate, the antioxidant compound was demarcated in situ with $0.2 \mathrm{mM}$ DPPH reagents (Belaqziz et al. 2017). Yellow spots marked areas against a purple background were considered as antioxidant compounds. This spot was scratched, centrifuged and collected for further study.

\section{Antioxidant activity}

\section{Chemicals}

Ascorbic acid (AA), quercetin (QR), 2,2-diphenyl-1-picrylhydrazyl (DPPH) and 2,2-azino-bis (3-ethylbenzthiazoline6sulphonic acid) $\left(\mathrm{ABTS}^{+}\right)$were purchased from Sigma (Sigma-Aldrich). Rutin, gallic acid and Folin-Ciocalteu's reagents were obtained from Merk. All other chemicals and reagents were procured locally and were of analytical grade.

\section{DPPH method}

In vitro antioxidant activity of each crude extract and purified compounds was performed using standard methodology (Shen, et al. 2010) with slight modifications. In this method, an aliquot of $1 \mathrm{~mL}$ of DPPH solution $(0.2 \mathrm{mM})$ prepared in methanol was contributed to a test tube having $3 \mathrm{~mL}$ of methanolic solution (containing $1000 \mu \mathrm{g}$ crude extract, and purified compounds in the range of 12.5, 25, $50,100,200$ and $400 \mu \mathrm{g})$. A percentage of antioxidant activity of purified compounds of EtOAcE (PDB) of EHL2 at different concentrations ranged from 12.5 to $400 \mu \mathrm{g}$ were compared with ascorbic acid (AA) and quercetin (QR), the positive standard antioxidant compounds. After $30 \mathrm{~min}$ of incubation in the dark, optical density was measured at $517 \mathrm{~nm}$ against a methanol blank using a UV-visible spectrophotometer (U-2900, Hitachi). There is an inverse relation between optical density and DPPH free radical inhibition. 
The effective concentration $\left(\mathrm{EC}_{50}\right)$ of purified compounds was also measured. The percentage of free radical inhibition (I) against control was calculated as [(Abs control - Abs test sample) $\div$ Abs control $\times 100]$. All the experiments were conducted in triplicates.

\section{ABTS method}

The ABTS assay is based on the ability of antioxidant compounds to scavenge 2,2-azino-bis (ethylbenzthiazoline6-sulfonic acid $\left(\mathrm{ABTS}^{+}\right)$free radical cations (Kaaniche et al. 2019). For this assay, a radical cation was prepared by mixing $7 \mathrm{mM}$ ABTS solution with $2.45 \mathrm{mM}$ potassium persulfate in equal volume and leaving the mixture for $15 \mathrm{~min}$ at room temperature in the dark. The $\mathrm{ABTS}^{+}$solution was diluted with ethanol to obtain the absorbance of $0.700 \pm 0.05$ at $734 \mathrm{~nm}$. In order to estimate the antioxidant potential of partial purified compounds of EtOAcE (PDB), $20 \mu \mathrm{L}$ sample of various concentrations ( 12.5 to $400 \mu \mathrm{g}$ ) was added to the test tube containing $2 \mathrm{~mL}$ ethanol with $1 \mathrm{~mL}$ of $\mathrm{ABTS}^{+}$ solution, and the mixture was vortexed for $30 \mathrm{~s}$. Using a spectrophotometer, absorbance was recorded immediately at $734 \mathrm{~nm}$. The $\mathrm{IC}_{50}$ value of the purified extract was measured. $\mathrm{AA}$ and $\mathrm{QR}$ were used as positive controls.

\section{GC/MS analysis}

The compounds separated by TLC were detected and identified using gas chromatography mass spectrometry (GC-MS) analysis. The analysis was carried out in GCMS QP 2010 added to Shimadzu ultra-gas chromatograph coupled with mass selective detector, and the pressure was maintained at $90.4 \mathrm{kpa}$. Helium gas was used as a carrier with a flow rate of $1.0 \mathrm{~mL} / \mathrm{min}$ and the pressure of the column head was maintained at 13.3psi. The injector temperature and injection volume were maintained at $260{ }^{\circ} \mathrm{C}$ and $1.21 \mathrm{ml} / \mathrm{min}$, respectively. The column temperature was set at $100{ }^{\circ} \mathrm{C}$, gradually increased to $280{ }^{\circ} \mathrm{C}$ at a rate of $5^{\circ} \mathrm{C} / \mathrm{min}$ for $5 \mathrm{~min}$, further programmed to $320^{\circ} \mathrm{C}$ for $19 \mathrm{~min}$. The mass spectra were scanned from $\mathrm{m} / \mathrm{z} 40$ to 700 with a speed of 3333 . The compounds were recognized based on the comparison of mass spectra in the National Institute of Standard and Technology (NIST) database.

\section{Statistical analysis}

All the values are expressed as means $(n=3) \pm$ standard deviation (SD). Analysis of variance was carried out and differences between variables were tested by one-way ANOVA with Tukey post hoc test using the SAS 8.0 program. $P<0.05$ was considered as suggestive of statistical significance. Correlation analysis was performed using the correlation and regression programme in the Microsoft EXCEL program.

\section{Results}

\section{Isolation and identification of fungal isolate, EHL2}

An endophytic fungus, EHL2, was isolated from the healthy leaf tissues of a medicinal plant, Euphorbia hirta, collected from the Botanical Garden of Banaras Hindu University (BHU), Varanasi, India. Preliminary characterization of EHL2 was done on its morphological features, including plate colony and growth pattern (Fig. S1a, b). Based on ITS 5.8S rDNA gene sequencing, followed by BLAST search tool with the NCBI database, it was identified as Nigrospora sphaerica EHL2 (code) with GenBank accession number MN726479.

\section{Fermentation and sequential extraction of fungal crude extract}

Sequentially isolated ethyl acetate extract of $N$. sphaerica fermented in PDB medium retained the maximum amount of crude extract $(51.33 \pm 0.57)$, while chloroform extract of the fungus fermented in MEB medium produced the minimal quantity of extract $(11.33 \pm 0.57)$. Moreover, PDB medium produced the largest amount of crude extract (167.66 \pm 1.15$)$, while it was the lowest $(91 \pm 1)$ in CDB medium (Table S1). Figure 1 shows the schematic diagram of sequential extraction of fungal endophyte fermented in various culture media.

\section{Qualitative phytochemical analysis of the sequentially extracted crude extract of $N$. sphaerica}

The results of qualitative phytochemical analysis of each crude extract are expressed as follows: $++++=$ very heavily present,$+++=$ heavily present,$++=$ present,$+=$ trace and $-=$ absent. EtOAcE of PDB medium showed a very heavy presence of phenolics and a heavy presence of alkaloids. Methanol extract of PDB medium represents a very heavy presence of flavonoids, while chloroform extract of CDB medium indicates the heavy presence of terpenoid compounds. Preliminary phytochemical analysis of sequentially extracted crude metabolites of the fungus, N. sphaerica, fermented in different growth media is presented in Table1.

\section{TPC and TFC determination of the sequentially extracted crude extract of $N$. sphaerica}

As shown in Table 2, the amounts of TPC and TFC differed when $N$. sphaerica were cultured in different media 


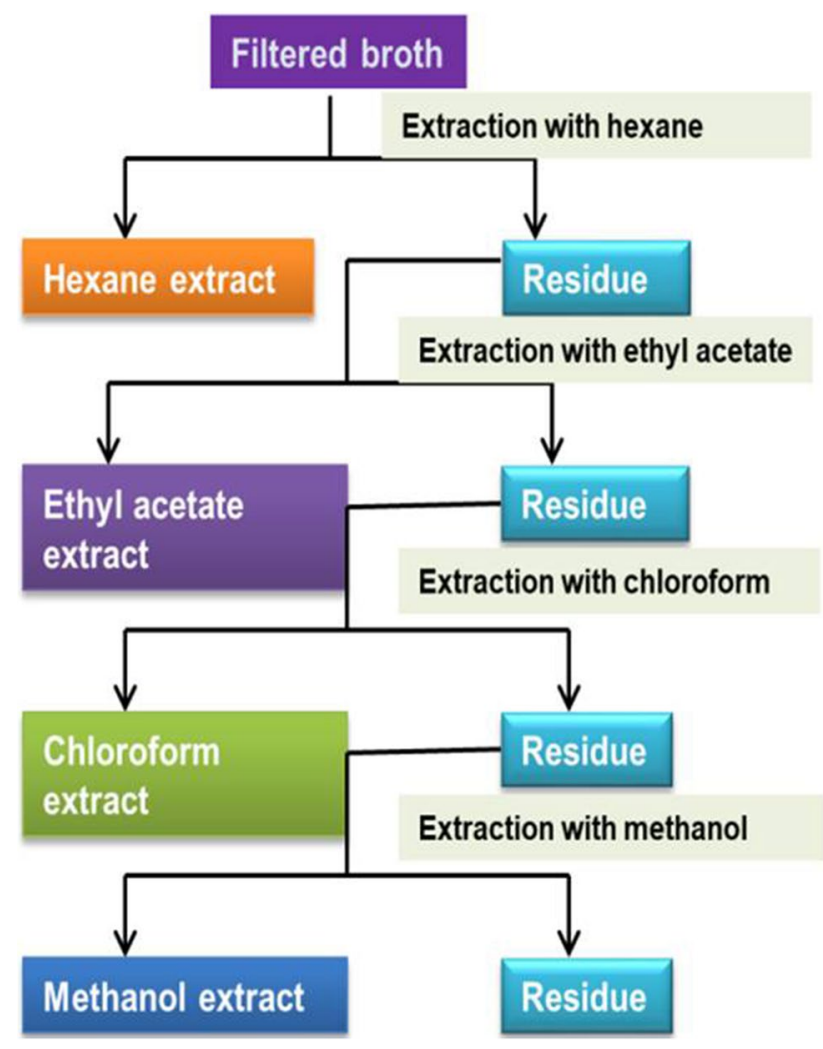

Fig. 1 Schematic diagram showing sequential extraction

and varied the extraction solvent. The level of TPC and TFC was the highest in EtOAcE $(77.74 \pm 0.04 \mathrm{mgGAE} / \mathrm{g}$ of crude extract for phenolic and $230.59 \pm 2.0 \mathrm{mgRE} / \mathrm{g}$ extract for flavonoids) of fungus fermented in PDB medium with the maximal antioxidant potential $(96.80 \%)$. However, the TPC and TFC were absent in the hexane extract of endophyte cultured in CDB medium, showing the lowest potential (4.63\%) for free radical scavenging.

\section{TLC bioautography-based detection and purification of antioxidants present in EtOAcE (PDB)}

In order to separate the antioxidant component present in the crude extract, TLC was performed prior to the bioautography assay. The TLC Plate was removed when the solvent reached $8.8 \mathrm{~cm}$ from the original extract loaded position. After drying, two yellow spots ( $\mathrm{R} f 0.18,0.50$ ) were visualized on the developed plate before derivatization (Fig. 2a). The number of spots varied in the post derivatization process depending on the wavelength of light: one spot ( $\mathrm{Rf} 0.18$ ) was visualized under visual light (700-400 nm) (Fig. 2b), three spots ( $\mathrm{Rf} 0.18,0.35,0.50)$ under short UV light $(254 \mathrm{~nm}$ ) (Fig. 2c), and one spot (Rf 0.18) under long UV light (366 nm) (Fig. 2d). The yellow colour reaction visualized at $\mathrm{Rf} 0.18$ in UV-visible light confirmed the presence of antioxidant compounds, which were collected for further study.

\section{Spectroscopy-assisted in vitro antioxidant assay of each crude extract and purified compounds}

\section{DPPH method}

In order to establish a relationship among each crude extract's TPC, TFC and antioxidant activity, statistical analysis was performed and correlated with its significant or insignificant values (Table 2). Antioxidant activity evaluated by the DPPH method was observed as a shift of the DPPH colour from purple to yellow. The free radical scavenging activity of partial purified compounds of EtOAcE (PDB) at $12.5,25,50,100,200$ and $400 \mu \mathrm{g}$ concentrations was $10.09,23.28,37.76,43.54,72.83$ and $91.18 \%$, respectively (Fig. S2a). The activity of the purified compound was less compared to that of the AA and QR at identical concentrations; however, the activity was almost equal to $\mathrm{QR}$ at $400 \mu \mathrm{g} / \mathrm{mL}$ concentration. Antioxidant activity of the purified compounds increased with the increasing concentration of metabolites (Fig. 3b). The calculated $\mathrm{IC}_{50}$ value of the purified compound was $148.5 \mu \mathrm{g} / \mathrm{mL}$.

\section{ABTS method}

The reduction of $\mathrm{ABTS}^{\bullet+}$ was done by reacting with low redox potential bearing phenolic compounds. The colour changed from blue-green to colourless. Activity of the purified crude compounds increased with the increasing concentration of extract. The free radical inhibition values of purified compounds of EtOAcE (PDB) at the concentrations of $12.5,25,50,100,200$ and $400 \mu \mathrm{g} / \mathrm{mL}$ were $16.96,46.81$, $66.05,73.93,86.43$ and $92.11 \%$, respectively (Fig. 2b). At equal concentrations, the antioxidant potential of the compounds was found to be relatively lower than that of AA and $\mathrm{QR}$, whereas at $400 \mu \mathrm{g} / \mathrm{mL}$ concentrations, the activity of the purified compounds increased rapidly $(92.11 \%)$, while QR and AA exhibited 94.69 and $98.02 \%$ antioxidant potential, respectively (Fig. 3a). The calculated $\mathrm{IC}_{50}$ value of the purified extract was $32.44 \mu \mathrm{g} / \mathrm{mL}$.

\section{GC-MS analysis of partial purified compounds of EtOAcE (PDB)}

Based on the MS library of NIST, several peaks were detected. All the major peaks were resolved and presented in the form of a chromatogram (Fig. 4a). A total of 13 peaks were observed from the GC-MS analysis. Table 3 shows the number of peaks or identified compounds, the retention time, the name of the compounds along with their molecular weight and molecular formula, and the percent area and 
Table 1 Qualitative phytochemical analysis of sequentially extracted crude extract of $N$. sphaerica fermented in various culture media

\begin{tabular}{|c|c|c|c|c|c|}
\hline Solvents/Media & Phenolics & Flavonoids & Terpenoids & Alkaloids & Glycosides \\
\hline \multicolumn{6}{|l|}{ Ethyl acetate } \\
\hline PDB & +++++ & ++ & + & +++ & - \\
\hline $\mathrm{CDB}$ & - & + & - & - & - \\
\hline CDYEB & ++ & + & + & + & + \\
\hline MEB & + & + & + & ++ & - \\
\hline SDB & - & - & - & - & - \\
\hline \multicolumn{6}{|l|}{ Chloroform } \\
\hline PDB & - & + & ++ & - & + \\
\hline $\mathrm{CDB}$ & - & - & +++ & - & + \\
\hline CDYEB & - & - & - & - & + \\
\hline MEB & - & - & - & - & + \\
\hline SDB & - & - & + & - & + \\
\hline \multicolumn{6}{|l|}{ Methanol } \\
\hline PDB & - & ++++ & - & - & - \\
\hline $\mathrm{CDB}$ & - & - & - & - & - \\
\hline CDYEB & - & - & - & - & - \\
\hline MEB & - & - & - & - & - \\
\hline SDB & - & - & - & - & - \\
\hline \multicolumn{6}{|l|}{ Hexane } \\
\hline PDB & - & - & + & - & - \\
\hline $\mathrm{CDB}$ & - & - & - & - & - \\
\hline CDYEB & - & - & - & - & - \\
\hline MEB & - & - & - & - & - \\
\hline SDB & - & - & - & - & - \\
\hline
\end{tabular}

- Not detected activity of the compounds. GC-MS analysis of the purified extract showed the highest peak area at $20.23 \mathrm{RT}$ with the presence of 9-hexacosene (13.83\%), followed by 2,4-Di-tertbutylphenol $(14.83 \%)$ at RT 14.39 , whereas 1-undecanol $(0.73 \%)$ showed the lowest \% composition at RT 8.65 and others (Table S2). Alkene grabbed the highest area of the chromatogram at $25 \%$, representing the dominance in purified crude extract, followed by hydrocarbons (17\%), phenolic compounds (14\%), alkane (14\%), ester (13\%), fatty alcohol (11\%) and fatty acid (6\%) (Fig. 4c).

\section{Discussion}

Based on morphological structure and molecular characterization, the endophytic fungus EHL2, isolated from the healthy leaf tissues of Euphorbia hirta, was identified as Nigrospora sphaerica. The fungus, N. sphaerica, has also been documented in a huge range of hosts, viz, Moringa oleifera, Ginkgo biloba, Saccharum arundinaceum and Phoenix dactylifera. Several antimicrobial bioactive compounds, such as nigrosporins, nigrosporolides and lactones, have previously been reported from Nigrospora sp. (Ramesha et al. 2020). However, information available on the antioxidant compounds of the species is scanty. In this study, $N$. sphaerica has been isolated for the first time as an endophyte from the healthy and disease-free leaves of E. hirta in search of prominent endophytic fungus, which could produce the antioxidant compounds. A variety of procedures and different media were used to obtain the maximum number of endophytes from unripe fruits and roots of Azadirachta indica (Verma et al. 2011). Unlike the previous study, various culture media were used for fungal fermentation in this study, and the effect of the media on various phytochemical groups was assessed using biochemical tests. Besides, sequential extraction of all filtrates was done to recover the total crude metabolites, which are left after extraction in a single solvent. In the phytochemical groups, phenols and terpenes are the chief biochemical constituents accountable for reducing lipid peroxidation, and that is why they act as primary and secondary antioxidants (Hijdu et al. 2007). The extract exhibited antiradical activity even after being low in the concentration of TPC and TFC. This might be because of the presence of other phytochemical groups, such as tannins, saponins and terpenoids, which could not be quantified in this experiment. Ethyl acetate extract of Penicillium sp. isolated from Mussaenda luteola exhibited both TPC and TFC, which were $24.38 \mathrm{mg}$ GAE/g and $15.62 \mathrm{mg}$ 
Table 2 Total phenolic, flavonoid contents and DPPH scavenging potential of different crude extracts of $N$. sphaerica

\begin{tabular}{|c|c|c|c|}
\hline $\begin{array}{l}\text { Media/ } \\
\text { Solvent }\end{array}$ & $\begin{array}{l}\text { Total phenolics } \\
\text { (mg GAE/ g crude } \\
\text { extract) }\end{array}$ & $\begin{array}{l}\text { Total flavonoids } \\
\text { (mg RE/g crude } \\
\text { extract) }\end{array}$ & $\begin{array}{l}\text { DPPH scav- } \\
\text { enging activity } \\
(\%)\end{array}$ \\
\hline \multicolumn{4}{|c|}{ Ethyl acetate } \\
\hline PDB & $77.74 \pm 0.046^{\mathrm{a}}$ & $230.59 \pm 2.00^{\mathrm{a}}$ & $96.80 \pm 0.24^{\mathrm{a}}$ \\
\hline CDB & $22.09 \pm 0.06^{\mathrm{e}}$ & $88.73 \pm 2.31^{\mathrm{d}}$ & $21.29 \pm .04^{\mathrm{e}}$ \\
\hline CDYEB & $53.04 \pm 0.04^{\mathrm{b}}$ & $123.53 \pm 3.06^{\mathrm{c}}$ & $68.69 \pm 0.75^{\mathrm{b}}$ \\
\hline SDB & $33.32 \pm 0.03^{\mathrm{d}}$ & $31.19 \pm 3.06^{\mathrm{e}}$ & $33.32 \pm 0.24^{\mathrm{d}}$ \\
\hline MEB & $45.06 \pm 0.46^{\mathrm{c}}$ & $134.23 \pm 4.01^{\mathrm{b}}$ & $50.86 \pm 0.43^{\mathrm{c}}$ \\
\hline \multicolumn{4}{|c|}{ Chloroform } \\
\hline PDB & $3.32 \pm 0.03^{\mathrm{d}}$ & - & $29.85 \pm 0.66^{\mathrm{b}}$ \\
\hline CDB & $7.43 \pm 0.06^{c}$ & - & $35.79 \pm 0.24^{\mathrm{a}}$ \\
\hline CDYEB & $7.32 \pm 0.01^{\mathrm{c}}$ & - & $35.35 \pm 0.25^{\mathrm{a}}$ \\
\hline SDB & $10.28 \pm 0.03^{b}$ & - & $16.22 \pm 0.25^{\mathrm{d}}$ \\
\hline MEB & $13.45 \pm 0.06^{\mathrm{a}}$ & - & $23.32 \pm 0.24^{\mathrm{c}}$ \\
\hline \multicolumn{4}{|l|}{ Methanol } \\
\hline PDB & $34.88 \pm 0.03^{\mathrm{b}}$ & $24.90 \pm 3.06^{\mathrm{b}}$ & $85.50 \pm 0.25^{\mathrm{a}}$ \\
\hline $\mathrm{CDB}$ & $2.10 \pm 0.01^{\mathrm{d}}$ & $15.54 \pm 2.00^{\mathrm{c}}$ & $21.15 \pm 0.66^{\mathrm{c}}$ \\
\hline CDYEB & $14.88 \pm 0.01^{\mathrm{c}}$ & - & $62.45 \pm 0.24^{\mathrm{b}}$ \\
\hline SDB & $52.26 \pm 0.03^{\mathrm{a}}$ & $54.34 \pm 3.06^{\mathrm{a}}$ & $86.37 \pm 0.50^{\mathrm{a}}$ \\
\hline MEB & $14.77 \pm 0.30^{c}$ & - & $87.82 \pm 0.43^{\mathrm{a}}$ \\
\hline \multicolumn{4}{|l|}{ Hexane } \\
\hline PDB & - & $44.98 \pm 3.06^{\mathrm{a}}$ & $72.60 \pm 0.60^{c}$ \\
\hline $\mathrm{CDB}$ & - & - & $4.63 \pm 2.75^{\mathrm{e}}$ \\
\hline CDYEB & - & - & $75.35 \pm 0.25^{\mathrm{b}}$ \\
\hline SDB & - & $6.18 \pm 3.06^{\mathrm{b}}$ & $78.83 \pm 0.25^{\mathrm{a}}$ \\
\hline MEB & - & - & $61.58 \pm 0.24^{\mathrm{d}}$ \\
\hline
\end{tabular}

Data are expressed as mean of three replicates \pm standard deviation. Means within each column with different letters (a-e) differ significantly $(P<0.05)$; - not detected

$\mathrm{RE} / \mathrm{g}$, respectively (Gunasekaran et al. 2017). Ethyl acetate extract of another endophytic fungus, Achaetomium sp. isolated from E. hirta, was estimated to have $218.16 \mathrm{mg} \mathrm{RE} / \mathrm{g}$ TFC (Anitha and Mythili 2017). Ethyl acetate solvent is the most efficient, and selectively extracts the high molecular weight polyphenols and low molecular weight phenolic components (Garcia et al. 2012; Scholz and Rimpler 1989). Most of the pigmented parts of culture media are soluble in this solvent and allow the highest phenolic content and permit selective removal of non-phenolic compounds (Anitha and Mythili 2017). The results indicated that the sequentially extracted EtOAcE (PDB) contains significantly more phenolic and flavonoid contents than that of some important endophytic fungi. Previous studies have ratified that there is a linear correlation between TPC and antioxidant capacity (Liu et al. 2007; Sultana et al. 2007). Similarly, there is a direct correlation between TFC and antioxidant activity of any sample (Fitriansyah et al. 2018). In the correlation analysis, it was found that there was a positive correlation between TFC and antioxidant activity, $R^{2}=0.762(P<0.05)$ of sequentially extracted EtOAcE (PDB), whereas a high positive correlation was noticed between TPC and free radical scavenging potential, $R^{2}=0.989(P<0.05)$ of the same extract (Table 2). However, no correlation was found among phenolic content, flavonoid content and antiradical activity of other crude extracts. The extracts that have shown an unclear relationship among TPC, TFC and antioxidant potential may be due to the crucial role of some compounds, like alkaloids and terpenoids, which were not estimated in this study. The antioxidant activity of crude extract is dependent on the concentration, along with the structure and interaction among the phenolic compounds.

The DPPH (0.2 $\mathrm{mM})$ solution was sprayed in situ, and a yellow colour reaction visualized at $\mathrm{Rf} 0.18$ under UV-visible light indicated the presence of phenolics, flavonoids and terpenoids, which could be responsible for the antioxidant activity (Fig. 4b). Spraying the plate with DPPH is more stable than that of ABTS and gives a more homogeneous colouring to the spots (Dewanjee et al. 2015). The TLC bioautography assay is the easiest screening method of antioxidant compounds due to several advantages that include simplicity, flexibility and high throughput. Since this technique provides a great platform by which antioxidant compounds can be detected in a cost-effective manner, several
Fig. 2 TLC plates of ethyl acetate extract (PDB) of Nigrospora sphaerica visualized under visible light before and after derivatization (0.2 Mm DPPH solutions), UV light at $254 \mathrm{~nm}$ (green panel) and $366 \mathrm{~nm}$ (blue panel)
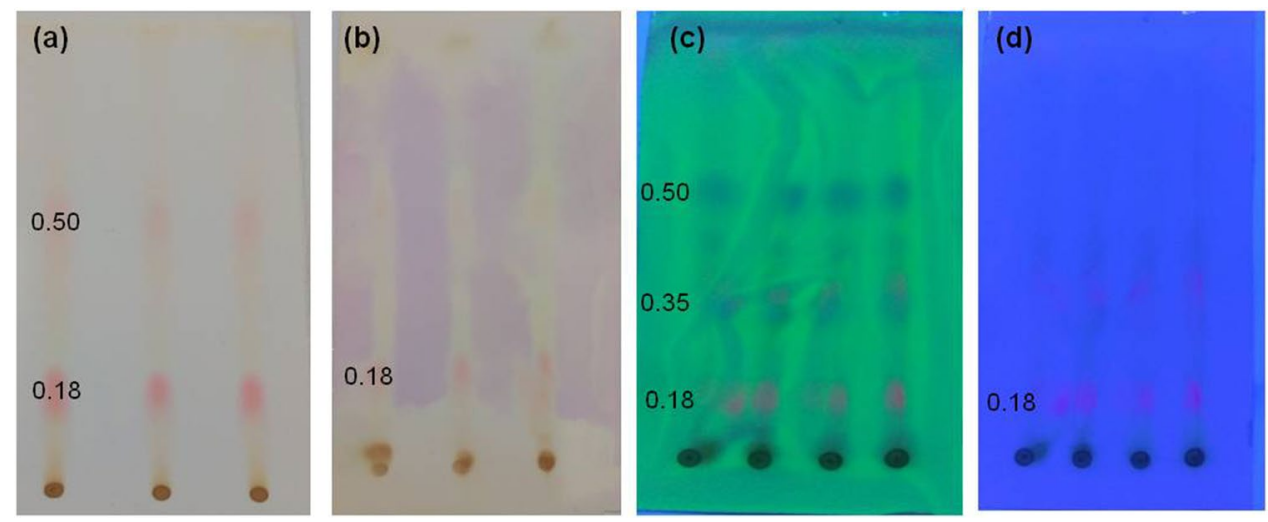
Fig. 3 a ABTS free radical inhibiting potential of purified ethyl acetate extract (PDB) of Nigrospora sphaerica and positive control using different concentrations $(12.5-400 \mu \mathrm{g})$ and b DPPH free radical scavenging potential of purified ethyl acetate extract (PDB) of $N$. sphaerica and positive control using different concentrations $(12.5-400 \mu \mathrm{g})$
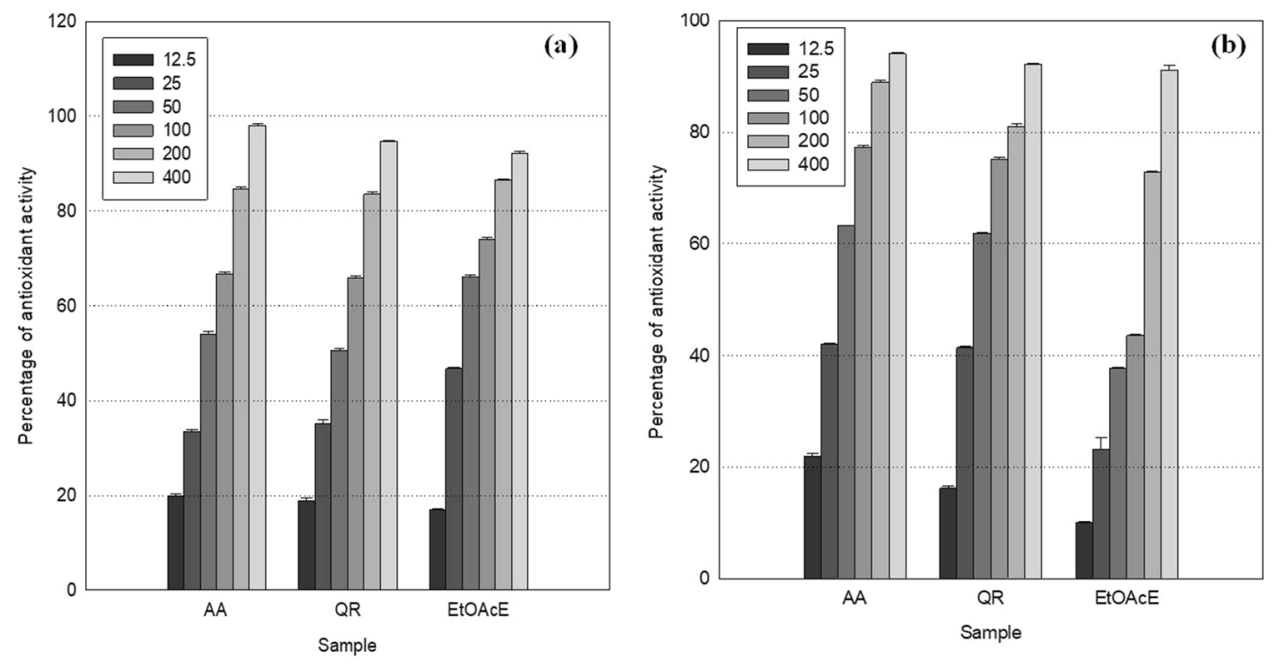

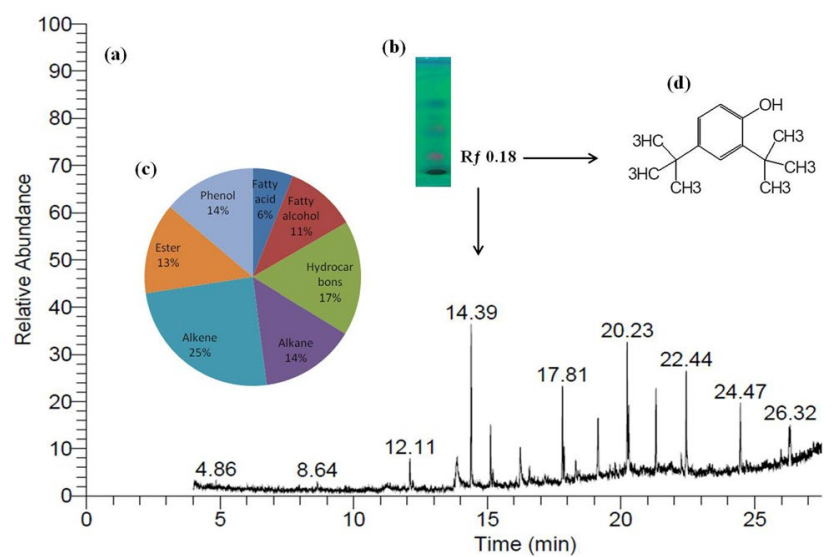

Fig. 4 a Chromatogram of GC-MS analysis, b TLC bioautographybased purification of compounds, $\mathbf{c}$ presence of different chemical groups in the partial purified ethyl acetate extract (PDB) and $\mathbf{d}$ depicting chemical structure of 2,4-Di-tert-butylphenol

antioxidant compounds have been identified, such as isoorientin and isoorientin 2"-O- $\alpha$-L-rhamnoside (Wang et al. 2012). The DPPH-dependent antioxidant assay is based on the reduction of DPPH in the presence of hydroxyl groups of antioxidant compounds due to the synthesis of the nonradical form DPPH-H (Shon et al. 2003). The antioxidant activity of $N$. sphaerica isolated from Artemisia herba alba and Chiliadenus montanus at $1000 \mu \mathrm{g} / \mathrm{mL}$ concentrations was $14 \%$ and $13 \%$, respectively (Selim et al.2018). However, antioxidant activity of EtOAcE (PDB) of the fungus $N$. sphaerica isolated from $E$. hirta at the same concentration $(1000 \mu \mathrm{g} / \mathrm{mL}$ ) was $96.80 \%$ (Table 2), while activity of the partial purified extract at the concentration of $400 \mu \mathrm{g}$ was $91.18 \%$ (Fig. 3b). Thus, the antioxidant scavenging potential of the crude extract is comparatively lower than that of the purified extract due to the less availability of antioxidant compounds in the crude of EtOAcE (PDB). In the present study, the $\mathrm{IC}_{50}$ value of the purified compounds was $148.5 \mu \mathrm{g} / \mathrm{mL}$, which was comparatively lower than that of the endophytic fungus Cytospora rhizophorae, obtained from $R$. stylosa, which had performed the most potent antiradical activity with an $\mathrm{IC}_{50}$ value of $330 \mu \mathrm{g} / \mathrm{mL}$ (Zhou et al. 2018). A low $\mathrm{IC}_{50}$ value reveals high antioxidant capacity. Therefore, the antiradical potential of the fungus $N$. sphaerica EHL2 is remarkably high compared to those of the previously reported endophytic fungus, and confirms that the antiradical nature of crude metabolites of endophytic fungi varies among fungi. When estimated by the ABTS method, the fungal endophyte Neopestalotiopsis protearum exhibited a lower $\mathrm{IC}_{50}$ value $(1240 \mu \mathrm{g} / \mathrm{mL})$ compared to that of the DPPH method $(1800 \mu \mathrm{g} / \mathrm{ml})$ (Zhou et al. 2018). The $\mathrm{IC}_{50}$ value observed in this study $(32.44 \mu \mathrm{g} / \mathrm{mL})$ was relatively lower than the above result estimated by the ABTS method, which has great antioxidant potential. During the reaction, antiradical molecules changed the blue-green colour of $\mathrm{ABTS}^{\bullet+}$ to a colourless neutral form, and the reduction of blue-green $\mathrm{ABTS}^{\bullet+}$ is studied by the suppression of its long wavelength absorption spectra. Thermodynamically, a compound may reduce $\mathrm{ABTS}^{\bullet+}$ if it has a redox potential lower than that of ABTS (0.68 V) (Antolovich et al. 2002; Apak et al. 2013). Several phenolic compounds react with $\mathrm{ABTS}^{\bullet+}$ due to low redox potential. $\mathrm{ABTS}^{\bullet+}$ can be used to determine the antioxidant activity of both hydrophilic and lipophilic compounds, because it is soluble in both inorganic and organic solvents. When a single method is selected to test antioxidant potential, the results may alter according to the time of reaction, solvent's choice, $\mathrm{pH}$ and standard employed (Alam et al. 2013).

To investigate the chemical composition of purified compounds of EtOAcE (PDB) and to validate the results of phytochemical analysis and TLC bioautography, the GC-MS technique was applied. In this technique, first, the sample mixture vapourizes and then separates its components, which 
Table 3 Phytochemical-compounds present in the TLC based purified extract of EtOAcE (PDB) determined by GC-MS analysis

\begin{tabular}{|c|c|c|c|c|c|c|c|}
\hline RT & Name of compound & $\mathrm{MF}^{\mathrm{a}}$ & $\begin{array}{l}\mathrm{MW}^{\mathrm{b}} \\
\mathrm{g} / \mathrm{mol}\end{array}$ & $\%$ Area & Category & Biological activity & Reference \\
\hline 8.65 & 1-Undecanol & $\mathrm{C}_{11} \mathrm{H}_{24} \mathrm{O}$ & 172.3 & 0.73 & Fatty alcohol & Antibacterial activity & Togashi et al. (2007) \\
\hline 12.11 & 6-Dodecene & $\mathrm{C}_{12} \mathrm{H}_{24}$ & 168.31 & 2.68 & $\begin{array}{l}\text { Unsaturated } \\
\text { aliphatic } \\
\text { hydrocarbon }\end{array}$ & - & - \\
\hline 13.86 & $\begin{array}{l}\text { 3-Isopropoxy-1,1,1,7,7,7- } \\
\text { hexamethyl-3,5,5- } \\
\text { tris(trimethylsiloxy) } \\
\text { tetrasiloxane }\end{array}$ & $\mathrm{C}_{18} \mathrm{H}_{52} \mathrm{O}_{7} \mathrm{Si}_{7}$ & 577.2 & 9.67 & Alkane & Like CNS stimulant & Khalid et al. (2019) \\
\hline 14.39 & 2,4-Di-tert-butylphenol & $\mathrm{C}_{14} \mathrm{H}_{22} \mathrm{O}$ & 206.32 & 13.83 & Alkylated phenol & $\begin{array}{l}\text { Antioxidant and cytotoxic } \\
\text { activity }\end{array}$ & Zhao et al. (2020) \\
\hline 15.13 & Cyclotridecane & $\mathrm{C}_{13} \mathrm{H}_{26}$ & 182.35 & 4.56 & Alkane & - & - \\
\hline 16.23 & $\begin{array}{l}\text { 2,4-Dihydroxybenzoic acid, } \\
\text { 3TMS derivative }\end{array}$ & $\mathrm{C}_{16} \mathrm{H}_{30} \mathrm{O}_{4} \mathrm{Si}_{3}$ & 370.66 & 6.04 & Fatty acid & - & - \\
\hline 17.81 & Heptacos-1-ene & $\mathrm{C}_{27} \mathrm{H}_{54}$ & 378.7 & 9.8 & Alkene & - & - \\
\hline 19.14 & $\begin{array}{l}\text { Phthalic acid, 5-methylhex- } \\
\text { 2-yl isobutyl ester }\end{array}$ & $\mathrm{C}_{19} \mathrm{H}_{28} \mathrm{O}_{4}$ & 320.4 & 6.54 & Ester & - & - \\
\hline 20.23 & 9-Hexacosene & $\mathrm{C}_{26} \mathrm{H}_{52}$ & 364.7 & 14.83 & Alkene & $\begin{array}{l}\text { Analgesic, Antiinflamma- } \\
\text { tory, Antinociceptive }\end{array}$ & Kuriuki et al. (2012) \\
\hline 21.31 & Vinyl 2-ethylhexanoate & $\mathrm{C}_{10} \mathrm{H}_{18} \mathrm{O}_{2}$ & 170.25 & 7.06 & Ester & - & - \\
\hline 22.44 & n-Tetracosanol-1 & $\mathrm{C}_{24} \mathrm{H}_{50} \mathrm{O}$ & 354.7 & 9.87 & Fatty alcohol & Anticancer & Vergara et al. (2015) \\
\hline 24.46 & $\begin{array}{l}\text { Octatriacontyl pentafluoro- } \\
\text { propionate }\end{array}$ & $\mathrm{C}_{41} \mathrm{H}_{77} \mathrm{~F}_{5} \mathrm{O}_{2}$ & 697 & 6.55 & Hydrocarbons & Anti covid 19 & H Elwakil et al. (2021) \\
\hline 26.33 & 17-Pentatriacontene & $\mathrm{C}_{35} \mathrm{H}_{70}$ & 490.9 & 7.85 & Hydrocarbons & Anticancer Antibacterial & Kumar et al. (2018) \\
\hline
\end{tabular}

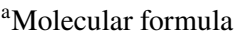

${ }^{\mathrm{b}}$ Molecular weight

are ionized and move through mass analysers. GC-MS is an excellent technique for identifying molecules/compounds, especially of low molecular weight that are both thermally stable and sufficiently volatile in nature.

GC-MS analysis of the purified compounds ratified the presence of various phytochemical groups with reported anticancer, antibacterial, anti-COVID-19 and other activities. The purified extract's highest chemical group was alkene $(25 \%)$, followed by hydrocarbons (17\%), alkane (14\%), phenol (14\%), ester (13\%), fatty alcohol (11\%) and fatty acid (6\%) (Fig. 4c).

The most important compound detected from the purified extract of EtOAcE (PDB) of EHL2 was 2,4-di-tert butyl phenol (2,4-DTBP) (Fig. 4d), a volatile phenolic compound (VPC). Compounds having aromatic rings in combination with tert-butyl groups, like 2,4-di-tert butyl phenols, are rather rare and have considerable antioxidant, and remarkable cytotoxic activity (Varsha et al. 2015). Besides, it is widely utilized in pharmaceuticals, fragrances and the plastic industry (Dembitsky 2006). 2,4-DTBP is reported to be present in fruits and seeds, which are responsible for antioxidant properties and act as an antioxidant agent (Varsha et al.2015). Moreover, 2,4-DTBP isolated from a fungal endophyte, Daldinia eschscholtzii, inhibits the quorum-sensing activity of Pseudomonas aeruginosa (Mishra et al.2020).

A recent review advocates that 2,4-DTBP is a common toxic compound that is produced by at least 169 species of microorganisms, plants and animals, including fungi (11 species), two of which are Colletotrichum gloeosporioides and Fusarium tricinctum (Zhao et al. 2020). Generally, anticancer activity in the cell line can be correlated with the antioxidant activity of the tested compounds (Grigalius and Petrikaite 2017). In this order, 2,4-DTBP displayed considerable anticancer activity with $10 \mu \mathrm{g} / \mathrm{mL}$ IC50 value against HeLa cells (Zhao et al. 2020). Based on the present and earlier reports, 2,4-DTBP has been proven to be a natural source of an antioxidant compound with very good activity.

\section{Conclusion}

The results presented in this study have demonstrated that the EtOAcE (PDB) exhibited the highest amount of TPC and TFC and was positively correlated with antioxidant activity. The antioxidant activity of the purified extract estimated by ABTS model reveals the presence of some phenolic compounds that have almost similar activity to quercetin, which 
has been ratified by the TLC bioautography result at $\mathrm{R} f 0.18$. GCMS analysis of the purified extract detected only a single antioxidant compound, 2,4-DTBP, and it may be due to the limitation of GCMS, which is able to detect predominantly non-polar compounds. For the complete detection of antioxidant compounds present in the purified extract, LCMS analysis can be done in future research. The toxicity of the purified extract with its antioxidant activity should be tested to corroborate its safety for use as a food additive. However, the work on complete purification, identification and mechanism of antioxidant compounds present at $\mathrm{Rf} 0.18$ is in progress. The results suggest that Nigrospora sphaerica is a potential source of natural antioxidants. This is the first elaborative and exclusive report on endophytic $N$. sphaerica isolated from Euphorbia hirta.

Supplementary Information The online version contains supplementary material available at https://doi.org/10.1007/s00203-021-02650-7.

Acknowledgements The authors are thankful to the Head and Coordinator, CAS and DST-FIST in Botany, Institute of Science, BHU, Varanasi, India, for providing essential research facilities. The authors appreciably acknowledge the ISLS, UGC-UPE, DST-PURSE and IOE (R/Dev/D/IoE/Incentive/2020-21/32181), BHU, Varanasi, India, for technical and minor financial help. RNK appreciates the SERB, DST, New Delhi, for the financial help (EEQ /2020/000549). This work was supported by the University Grant Commission (UGC), New Delhi, as Junior Research Fellowship (JRF) and Senior Research Fellowship (SRF).

Author contributions VSG conceived the research, analysed the data and wrote the manuscript, and all the co-authors (AS, PK, JHN, JK, MY, RB, PP) contributed to conceptualization, experimental work, data collection and manuscript preparation, while RNK helped in conceptualization, provided the consumables and corrected the manuscript.

Funding This research did not receive any specific grant from the funding agencies; however, the consumables have been used from SERB (Grant No: EEQ/2020/000549), New Delhi, and IoE, BHU.

Availability of data and material All data associated with the work are mentioned in the manuscript.

\section{Declarations}

Conflict of interest The authors declare that they have no conflicts of interest.

Consent for publication All the authors read and are aware of publishing of the manuscript.

\section{References}

Abdel-Rahman T, Hussein AS, Beshir S, Hamed AR, Ali E, El-Tanany SS (2019) Antimicrobial activity of terpenoids extracted from Annona muricata seeds and its endophytic, Aspergillus niger Strain SH3 either singly or in combination. Open Access Maced J Med Sci 7(19):3127. https://doi.org/10.3889/oamjms.2019.793
Ajuru MG, Williams LF, Ajuru G (2017) Qualitative and quantitative phytochemical screening of some plants used in ethnomedicine in the Niger delta region of Nigeria. J Food Sci Nutr 5:198-205

Alam MN, Bristi NJ, Rafiquzzaman M (2013) Review on in vivo and in vitro methods evaluation of antioxidant activity. Saudi Pharm J 21:143-152. https://doi.org/10.1016/j.jsps.2012.05.002

Anitha KU, Mythili S (2017) Antioxidant and hepatoprotective potentials of novel endophytic fungus Chaetomium sp., from Euphorbia hirta. Asian Pac J Trop Med 10:588-593. https:// doi.org/10.1016/j.apjtm.2017.06.00-8

Antolovich M, Prenzler PD, Patsalides E, McDonald S, Robards K (2002) Methods for testing antioxidant activity. Analyst 127:183-198. https://doi.org/10.1039/B00917-1

Apak R, Gorinstein S, Bohm V, Schaich KM, Ozyurek M, Guçlu K (2013) Methods of measurement and evaluation of natural antioxidant capacity/activity (IUPAC Technical Report). Pure Appl Chem 85:957-998. https://doi.org/10.1351/PAC-REP-12-07-15

Belaqziz M, Tan SP, El-Abbassi A, Kiai H, Hafidi A, O’Donovan O, McLoughlin P (2017) Assessment of the antioxidant and antibacterial activities of different olive processing waste waters. PLoS ONE 12:e0182622. https://doi.org/10.1371/journal.pone. 0182622

Dembitsky VM (2006) Natural neo acids and neo alkanes: their analogs and derivatives. Lipids 41:309-340. https://doi.org/10.1007/ s11745-006-51039

Devi NN, Prabakaran JJ, Wahab F (2006) Phytochemical analysis and enzyme analysis of endophytic fungi from Centella asiatica. Asian Pac J Trop Biomed 2:S1280-S1284. https://doi.org/10. 1016/S2221-1691(12)60400-6

Dewanjee S, Gangopadhyay M, Bhattacharya N, Khanra R, Dua TK (2015) Bioautography and its scope in the field of natural product chemistry. J Pharm Anal 5:75-84. https://doi.org/10.1016/j.jpha. 2014.06.002

Elwakil HB, Shaaban MM, Bekhit AA, El-Naggar MY, Olama ZA (2021) Potential anti-COVID-19 activity of Egyptian propolis using computational modeling. Fut Virol 16:107-116. https:// doi.org/10.2217/fvl-2020-0329

Fang YZ, Yang S, Wu G (2002) Free radicals, antioxidants, and nutrition. Nutrition 18:872-879. https://doi.org/10.1016/S08999007(02)00916-4

Fitriansyah SN, Aulifa DL, Febriani Y, Sapitri E (2018) Correlation of total phenolic, flavonoid and carotenoid content of Phyllanthus emblica extract from Bandung with DPPH scavenging activities. Pharmacogn J. https://doi.org/10.5530/pj.2018.3.7-3

Garcia A, Rhoden SA, Bernardi-Wenzel J, Orlandelli RC, Azevedo JL, Pamphile JA (2012) Antimicrobial activity of crude extracts of endophytic fungi isolated from medicinal plant Sapindus saponaria L. J Appl Pharm Sci 2:35. https://doi.org/10.7324/JAPS. 2012.21007

Grigalius I, Petrikaite V (2017) Relationship between antioxidant and anticancer activity of trihydroxyflavones. Molecules 22:2169. https://doi.org/10.3390/molecules2212216-9

Gunasekaran S, Sathiavelu M, Arunachalam S (2017) In vitro antioxidant and antibacterial activity of endophytic fungi isolated from Mussaenda luteola. J Appl Pharm Sci 7:234-238. https://doi.org/ 10.7324/JAPS.2017.70832

Hajdú Z, Hohmann J, Forgo P, Martinek T, Dervarics M, Zupkó I, Falkay G, Cossuta D, Máthé I (2007) Diterpenoids and flavonoids from the fruits of Vitex agnus-castus and antioxidant activity of the fruit extracts and their constituents. Phytother Res 21:391394. https://doi.org/10.1002/ptr.2021

Kaaniche F, Hamed A, Abdel-Razek AS, Wibberg D, Abdissa N, El Euch IZ, Allouche N, Mellouli L, Shaaban M, Sewald N (2019) Bioactive secondary metabolites from new endophytic fungus Curvularia sp. isolated from Rauwolfia macrophylla. PLoS One 14:e217627. https://doi.org/10.1371/journal.pone.0217627 
Kariuki DK, Kanui TI, Mbugua PM, Githinji CG (2012) Analgesic and anti-inflammatory activities of 9-Hexacosene and Stigmasterol isolated from Mondia whytei. Phytopharmacology 2(1):212-223

Khalid A, Alhazmi HA, Abdalla AN, Ahsan W, Sultana S, Al Bratty M, Javed SA (2019) GC-MS analysis and cytotoxicity evaluation of shammah (smokeless tobacco) samples of Jazan region of Saudi Arabia as promoter of cancer cell proliferation. J Chem. https:// doi.org/10.1155/2019/325483-6

Kohen R, Nyska A (2002) Invited review: oxidation of biological systems: oxidative stress phenomena, antioxidants, redox reactions, and methods for their quantification. Toxicol Pathol 30:620-650. https://doi.org/10.1080/01926230290166724

Kumar D, Karthik M, Rajakumar R (2018) GC-MS analysis of bioactive compounds from ethanolic leaves extract of Eichhornia crassipes (Mart) Solms. and their pharmacological activities. Pharma Innov J 7:459-462

Kumari P, Singh A, Singh DK, Sharma VK, Kumar J, Gupta VK, Bhattacharya S, Kharwar RN (2021) Isolation and purification of bioactive metabolites from an endophytic fungus Penicillium citrinum of Azadirachta indica. S Afr J Bot 139:449-457. https:// doi.org/10.1016/j.sajb.2021.02.02-0

Liu X, Dong M, Chen X, Jiang M, Lv X, Yan G (2007) Antioxidant activity and phenolics of an endophytic Xylaria sp. from Ginkgo biloba. Food Chem 105:548-554. https://doi.org/10.1016/j.foodc hem.2007.04.008

Mau JL, Lin HC, Chen CC (2002) Antioxidant properties of several medicinal mushrooms. J Agric Food Chem 50:6072-6077. https:// doi.org/10.1021/jf0201273

Mishra R, Kushveer JS, Khan M, Imran K, Pagal S, Meena CK, Venkateswara Sarma V (2020) 2, 4-Di-tert-butylphenol isolated from an endophytic fungus, Daldinia eschscholtzii, reduces virulence and quorum sensing in Pseudomonas aeruginosa. Front Microbiol 11:1668. https://doi.org/10.3389/fmicb.2020.0166-8

Muhammad Q, Gilani SN, Shahid F, Abdur R, Rifat N, Samreen P (2012) Preliminary comparative phytochemical screening of Euphorbia species. Eurasian J Agric Environ Sci 12:1056-1060. https://doi.org/10.5829/idosi.aejaes.2012.12.08.1798

Ramesha KP, Mohana NC, Nuthan BR, Rakshith D, Satish S (2020) Antimicrobial metabolite profiling of Nigrospora sphaerica from Adiantum philippense L. J Genet Eng Biotechnol 18:1-9. https:// doi.org/10.1186/s43141-020-00080-4

Scholz E, Rimpler H (1989) Proanthocyanidins from Krameria triandra root. Planta Med 55:379-384. https://doi.org/10. 1055/s-2006-962032

Selim KA, Elkhateeb WA, Tawila AM, El-Beih AA, Abdel-Rahman TM, El-Diwany AI, Ahmed EF (2018) Antiviral and antioxidant potential of fungal endophytes of Egyptian medicinal plants. Fermentation 4:49. https://doi.org/10.3390/fermentation403004-9

Sharma VK, Kumar J, Singh DK, Mishra A, Verma SK, Gond SK, Kumar A, Singh N, Kharwar RN (2017) Induction of cryptic and bioactive metabolites through natural dietary components in an endophytic fungus Colletotrichum gloeosporioides (Penz.) Sacc. Front Microbiol 8:1126. https://doi.org/10.3389/fmicb.2017. 01126

Shen Q, Zhang B, Xu R, Wang Y, Ding X, Li P (2010) Antioxidant activity in vitro of the selenium-contained protein from the Seenriched Bifidobacterium animalis 01. Anaerobe 16:380-386. https://doi.org/10.1016/j.anaerobe.2010.06.006

Shon MY, Kim TH, Sung NJ (2003) Antioxidants and free radical scavenging activity of Phellinus baumii (Phellinus of Hymenochaetaceae) extracts. Food Chem 82:593-597. https://doi.org/10. 1016/S0308-8146(03)000153

Siddhuraju P, Manian S (2007) The antioxidant activity and free radical-scavenging capacity of dietary phenolic extracts from horse gram (Macrotyloma uniflorum (Lam.) Verdc.) seeds. Food Chem 105:950-958. https://doi.org/10.1016/j.foodchem.2007.04.04-0
Singh A, Singh DK, Surendra K, Gond DK, Kharwar RN, James FW (2021) Fungal endophytes as efficient sources of plant-derived bioactive compounds and their prospective applications in natural product drug discovery: insights avenues and challenges. Microorganisms 9:1. https://doi.org/10.3390/microorganisms9 010197

Su LJ, Mahabir S, Ellison GL, McGuinn LA, Reid BC (2012) Epigenetic contributions to the relationship between cancer and dietary intake of nutrients, bioactive food components, and environmental toxicants. Front Genet 2:91. https://doi.org/10.3389/fgene.2011. 0009-1

Sultana B, Anwar F, Przybylski R (2007) Antioxidant activity of phenolic components present in barks of Azadirachta indica, Terminalia arjuna, Acacia nilotica, and Eugenia jambolana Lam. trees. Food Chem 104:1106-1114. https://doi.org/10.1016/j.foodchem. 2007.01.019

Sun B, Fukuhara M (1997) Effects of co-administration of butylated hydroxytoluene, butylated hydroxyanisole and flavonoids on the activation of mutagens and drug-metabolizing enzymes in mice. Toxicology 122:61-72. https://doi.org/10.1016/S0300-483X(97) 00078-4

Tan BL, Norhaizan ME, Liew WPP, Sulaiman Rahman H (2018) Antioxidant and oxidative stress: a mutual interplay in age-related diseases. Front Pharmacol 9:1162. https://doi.org/10.3389/fphar. 2018.0116-2

Tepal P (2016) Phytochemical screening, total flavonoid and phenolic content assays of various solvent extracts of tepal of Musa paradisiaca. Malaysian J Anal Sci 20:1181-1190

Togashi N, Shiraishi A, Nishizaka M, Matsuoka K, Endo K, Hamashima H, Inoue Y (2007) Antibacterial activity of longchain fatty alcohols against Staphylococcus aureus. Molecules 12:139-148. https://doi.org/10.3390/1202013-9

Varsha KK, Devendra L, Shilpa G, Priya S, Pandey A, Nampoothiri KM (2015) 2, 4-Di-tert-butyl phenol as the antifungal, antioxidant bioactive purified from a newly isolated Lactococcus $\mathrm{sp}$. Int $\mathbf{J}$ Food Microbiol 211:44-50. https://doi.org/10.1016/j.ijfoodmicro. 2015.06.025

Vergara M, Olivares A, Altamirano C (2015) Antiproliferative evaluation of tall-oil docosanol and tetracosanol over CHO-K1 and human melanoma cells. Electron J Biotechnol 18:291-294. https:// doi.org/10.1016/j.ejbt.2015.05.004

Verma VC, Kharwar RN, Strobel GA (2009) Chemical and functional diversity of natural products from plant associated endophytic fungi. Nat Prod Commun 4:1511-1532. https://doi.org/10.1177/ 1934578 X0900401114

Verma VC, Gond SK, Kumar A, Kharwar RN, Boulanger LA, Strobel GA (2011) Endophytic fungal flora from roots and fruits of an Indian neem plant Azadirachta indica A. Juss., and impact of culture media on their isolation. Indian J Microbiol 51:469-476. https://doi.org/10.1007/s12088-011-0121-6

Verma SK, Mishra A, Sharma VK, Gond SK, Kumar A, Kharwar RN (2014) Impact of environmental variables on the isolation, diversity and antimicrobial activity of endophytic fungal communities from Madhuka indica Gmel. at different location of India. Ann Microbiol 64:721-734. https://doi.org/10.1007/ s13213-013-0707-9

Wang J, Yue YD, Tang F, Sun J (2012) TLC screening for antioxidant activity of extracts from fifteen bamboo species and identification of antioxidant flavone glycosides from leaves of Bambusa. textilis McClure. Molecules 17:12297-12311. https://doi.org/10. 3390/molecules 171012297

Zhao F, Wang P, Lucardi RD, Su Z, Li S (2020) Natural sources and bioactivities of 2, 4-di-tert-butylphenol and its analogs. Toxins 12:35. https://doi.org/10.3390/toxins1201003-5

Zhishen J, Mengcheng T, Jianming W (1999) The determination of flavonoid contents in mulberry and their scavenging effects on 
superoxide radicals. Food Chem 64:555-559. https://doi.org/10. 1016/S0308-8146(98)00102-2

Zhou J, Diao X, Wang T, Chen G, Lin Q, Yang X, Xu J (2018) Phylogenetic diversity and antioxidant activities of culturable fungal endophytes associated with the mangrove species Rhizophora stylosa and $R$. mucronata in the South China Sea. PLoS One 13:0197359. https://doi.org/10.1371/journal.pone.0197359
Publisher's Note Springer Nature remains neutral with regard to jurisdictional claims in published maps and institutional affiliations. 